\title{
InFLATION Pressure and DyNAMic LOAd EFfects ON SOIL DEFORMATION AND SOIL-TIRE INTERFACE STRESSES
}

\author{
R. L. Raper, A. C. Bailey, E. C. Burt, T. R. Way, P. Liberati
}

\begin{abstract}
An 18.4 R38 R-1 radial tractor tire at inflation pressures of 41 and $124 \mathrm{kPa}$ and at dynamic loads of 13.1 and $25.3 \mathrm{kN}$ was evaluated to determine the effects of the new load-inflation pressure tables on soil deformation and contact stresses. Measurements of rut width and deformed rut area were conducted with a profile meter. Soil-tire interface stress measurements were also made to determine stresses occurring between the tire and the soil and to determine the tire footprint length. Inflation pressure and dynamic load effects were found on rut width, contact length. and contact area. Dynamic load effects were also found or deformed rut area. Increased levels of soil-tire interface stress was found near the center of the tire when inflation pressure or dynamic load was increased. Keywords. Radial tires. Ruts, Contact length.
\end{abstract}

T raction device design has made tremendous strides in the past 75 years. At the beginning of this era, researchers were attempting to improve the tractive characteristics of steel wheeled vehicles. The term "inflation pressure" for tractors had no meaning. However, it did not take long for farmers to recognize the superior tractive characteristics of pneumatic tires. According to Forrest (1954). the first commercial pneumatic tractor tire was offered in 1932. This opened the door for improvements in tractive performance that could not even have been imagined 10 years earlier. Another milestone was accomplished when radial tires were introduced (Forrest et al., 1962). These tires offered the capability of allowing farmers to put "more rubber on the road" thereby increasing the tractive effectiveness of their vehicle.

However, some farmers were not able to take advantage of the tractive advantages of radial tractor tires. In certain soil conditions, an unsafe oscillatory motion caused large four-wheel-drive tractors to hop uncontrollably when equipped with radial tires. This problem was termed "power hop" (Wiley et al., 1992). This problem mainly plagued radial tires and many farmers reverted to the biasply tires they had abandoned (Reichenberger, 1992). When they did this, they also lost the larger footprint and the tractive advantage of radial tires.

The agricultural equipment industry together with the agricultural tire industry announced in 1992 that most

Article was submitted in April 1994; reviewed and approved for publication by the Power and Machinery Div. of ASAE in February 1995. Presented as ASAE Paper No. 93-1517.

The use of companies or tradenames or company names does not imply endorsement by USDA-Agricultural Research Service.

The authors are Randy L. Raper, ASAE Member Engineer, Agricultural Engineer, Alvin C. Bailey, ASAE Member Engineer, Agricultural Engineer, and Thomas R. Way, ASAE Member Engineer, Agricultural Engineer, Eddie C. Burt, ASAE Member Engineer, Research Leader, USDA-Agricultural Research Service, National Soil Dynamics Laboratory, Auburn, Ala.; and Paolo Liberati, Visiting Scientist, Institute of Farm Machinery and Agricultural Mechanization, University of Bologna, Bologna, Italy. power hop problems could be solved by proper sizing, proper ballasting, and by the correct adjustment of inflation pressure (John Deere, 1992; Goodyear, 1992; Firestone, 1992). The importance of inflation pressure is central to this recommended solution. As researchers struggled to understand power hop, they found radial tires could operate with improved performance at significantly reduced levels of inflation pressure (Wiley et al., 1992). This information was used by the agricultural tire industry to extend their load-inflation pressure tables to lower inflation pressures. The new tables extend down to inflation pressures of $41 \mathrm{kPa}$ instead of the previous lower limit of $82 \mathrm{kPa}$.

These lower inflation pressures offer distinct advantages for radial tin: operation. As inflation pressure decreases, the footprint of the tire increases, increasing traction of the tire as well as decreasing soil compaction (Bailey et al., 1993; Raper et al., 1993). Other research has also shown the positive benefits of reduced inflation pressure (Burt and Bailey, 1982; Erbach and Knoll, 1982; Wood and Mangione, 1992).

Little public information is available on the tractive performance of American radial tractor tires at the lower inflation pressure levels recommended in the new loadinflation pressure tables. Of particular interest is how the tire contacts and gains traction in soil at low inflation pressures. The tire contact area has been studied on rigid surfaces (Abeels, 1976; Komandi, 1976; Upadhyaya and Wulfsohn, 1990). but little information is available about the actual rut that is created by a tire operating in soil. An increased understanding of how low inflation pressure levels enable tires to improve tractive performance could lead to even further advances in tractive performance and further reductions in soil compaction.

The objectives of this research were to determine the effect of inflation pressure and dynamic load on:

- Rut width and rut cross-sectional area as measured by a profile meter.

- Tire contact length and contact area as measured by soil-tire interface transducers.

- Soil-tire interface stress distribution across the lug of the tire. 


\section{Methods And Materials}

An experiment was conducted in the soil bins at the USDA-Agricultural Research Service, National Soil Dynamics Laboratory in Auburn, Alabama, to investigate the effect of inflation pressure and dynamic load on tire and soil parameters. Soils chosen for the study were a Norfolk sandy loam soil (Typic Paleudults) and a Decatur clay loam soil (Rodic Paleudults) (table 1). Both soils are from the southeastern United States and they contain a wide range of particle size distributions. These soils were selected because they are located indoors which facilitates the maintenance of a constant moisture content for an extended period of time.

Two soil conditions were created in each soil bin to give a different operating environment for the tire. A hardpan condition was created in both soil bins to simulate a condition that is commonly found in the southeastern United States in Coastal Plains areas. This hardpan is usually 0.2 to $0.3 \mathrm{~m}$ below the soil surface and it is quite impervious to root growth, particularly at low moisture levels. The hardpan was simulated by using a moldboard plow to laterally move the soil while using a rigid wheel to compact the soil left exposed in the plow furrow. This procedure was repeated until the entire bin has been traversed. The surface soil was then bladed and leveled. Variations can occur between bins, but within a bin the same depth of the hardpan can usually be achieved with little error. For the Norfolk sandy loam soil, the hardpan depth established was at $0.41 \mathrm{~m}$ and for the Decatur clay loam soil, the hardpan depth established was at $0.29 \mathrm{~m}$.

The other soil condition was a uniformly loose condition which was created by operating a rototiller to a depth of approximately $0.6 \mathrm{~m}$. Beginning values of bulk density, moisture content, and cone index for various depths arc found in table 1.

The tire used for the experiment was a Goodyear 18.4 R38 Dyna Torque Radial (2 star) R-1 agricultural tractor tire. This tire was mounted on the Traction Research

Table 1. Soil measurements showing the initial soil condition or the two indoor soil bins at the NSDL used for this experiment

\begin{tabular}{|c|c|c|c|}
\hline Depth $(\mathrm{cm})$ & $\begin{array}{c}\text { Bulk Density } \\
\left(\mathrm{Mg} / \mathrm{m}^{3}\right)\end{array}$ & $\begin{array}{c}\text { Moisture } \\
\text { Content }(\% \mathrm{db})\end{array}$ & $\begin{array}{c}\text { Cone Index } \\
(\mathrm{MPa})\end{array}$ \\
\hline \multicolumn{4}{|c|}{ Norfolk Sandy Loam Soil (Sand $72 \%$, Silt $17 \%$ Clay 11\%) } \\
\hline \multicolumn{4}{|c|}{ Hard Pan } \\
\hline $1-5$ & 1.18 & 6.4 & 0.17 \\
\hline $36-40$ & 1.32 & 7.1 & 0.72 \\
\hline $42-46$ & 1.89 & 7.8 & 6.03 \\
\hline \multicolumn{4}{|c|}{ Uniformly Loose } \\
\hline $1-5$ & 1.24 & 7.6 & 0.14 \\
\hline $32-36$ & 1.19 & 7.7 & 0.94 \\
\hline $40-44$ & 1.19 & 7.6 & 1.10 \\
\hline \multicolumn{4}{|c|}{ Decatur Clay Loam Soil (Sand $27 \%$, Silt $43 \%$, Clay $30 \%$ ) } \\
\hline \multicolumn{4}{|c|}{ Hard Pan } \\
\hline $1-5$ & 1.06 & 11.7 & 0.14 \\
\hline $24-28$ & 1.10 & 12.9 & 0.98 \\
\hline 30-34 & 1.81 & 15.2 & 3.82 \\
\hline \multicolumn{4}{|c|}{ Uniformly Loose } \\
\hline $1-5$ & 1.16 & 14.6 & 0.16 \\
\hline $25-29$ & 1.08 & 13.4 & 1.26 \\
\hline $31-35$ & 1.15 & 13.3 & 1.54 \\
\hline
\end{tabular}

Vehicle which has the capability of controlling dynamic load, inflation pressure, slip, and input torque as described by Burt et al. (1980) and Lyne et al. (1983). For this experiment a constant slip value of $10 \%$ and a constant forward velocity of $0.15 \mathrm{~m} / \mathrm{s}$ was chosen.

Four combinations of inflation pressure and dynamic load were used for this experiment. A two by two factorial was created with dynamic loads of 13.1 and $25.3 \mathrm{kN}$ and inflation pressures of 41 and $124 \mathrm{kPa}$. The key used for this article refers first to dynamic load and then inflation pressure. The 13.1 - 41 and the 25.3 - 124 load condition come directly from the dynamic load-inflation pressure tables supplied from the tire manufacturer (Goodyear, 1992). The 25.3 - 41 dynamic load-inflation pressure combination represents an overloaded tire condition which should not be practiced by farmers but is useful for experimental purposes. The 13.1 - 124 dynamic loadinflation pressure combination represents an underloaded tire condition with excessive inflation pressure for the load. However, the 13.1 - 124 load condition is a typical scenario found on farms throughout the United States. Four replications of these loads were conducted in each soil bin in each soil condition.

Each of the two soil types and two soil conditions was considered as a separate experiment with a randomized complete block design and a factorial treatment structure. This procedure created a set of four separate experiments. The ANOVAs across the four experiments were combined and soil became a fixed effect of the two soil types and the two soil conditions.

Seven commercially available Sensotec pressure transducers were mounted flush with the tread surface both on the lug and in the undertread area, to measure the soiltire interface stresses (fig. 1). Four of these transducers were mounted on the lug and three in the undertread area. The physical dimensions of these transducers are $1.1 \times 1.6$ $\mathrm{x} 0.2 \mathrm{~cm}$. Data was collected from these transducers at approximately every $2^{\circ}$ of tire rotational angle.

The soil-tire interface data were used to determine the length of tire that was in contact with the soil. The interface stresses on the lugs indicate when the transducers come into contact and when they are no longer in contact with the soil. By using the contact angle along with the rolling radios of the tire and the law of cosines, a contact length can be established for each transducer mounted on the lugs.

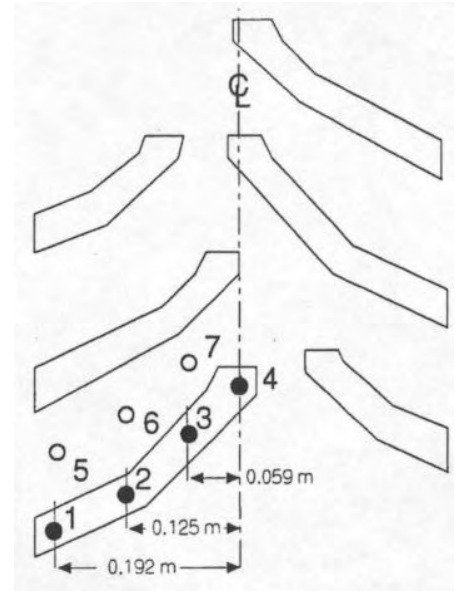

Figure 1-Locations of the soil-tire interface transducers on the $18.4 \mathrm{R38}$ radial tire. 
If an assumption is made about the width of the lug that each transducer represents, then a total contact area for the tire can be calculated.

A profile meter was used at the conclusion of each run to measure the rut width and the total deformed area. Photographs were taken of each rut and the data digitized on a SUN workstation using imaging software. The total disturbed width was measured across the rut and the total cross-sectional deformed rut area established.

Stress state transducers (SST) were placed beneath the center of the tire to measure the soil stress. An analysis of SST peak values was reported by Bailey et al. (1993).

Several other soil measurements were made after tests had been completed in each soil bin. These included cone index measurements taken with the NSDL penetrometer car in undisturbed areas, in the center of the tire lug print area, and at the edge of the tire lug print area. Measurements of bulk density and moisture content were also taken in the center of the tire footprint and in undisturbed areas.

\section{Results AND Discussion}

As inflation pressure was increased, rut width was decreased (fig. 2). This statistically significant result $(\mathrm{p}<0.0001)$ was found when data of both soil types and both soil conditions were combined. As the inflation pressure increased, the tire became narrower with less bulge near the side of the tire. When dynamic load was increased, rut width also tended to increase across both soil types and both soil conditions $(\mathrm{p}<0.0001)$. This effect was probably due to the bulge on the side of the tire penetrating further into the soil and being measured as increased width.

Total deformed cross-sectional area as measured by the profile meter was not affected by inflation pressure (p < 0.5356) (fig. 3). This occurred because increased inflation pressure caused decreased rut width and increased rut depth. These two parameters tended to cancel as each affects rut area in a different manner. Dynamic load effects were statistically significant, however, with increased load

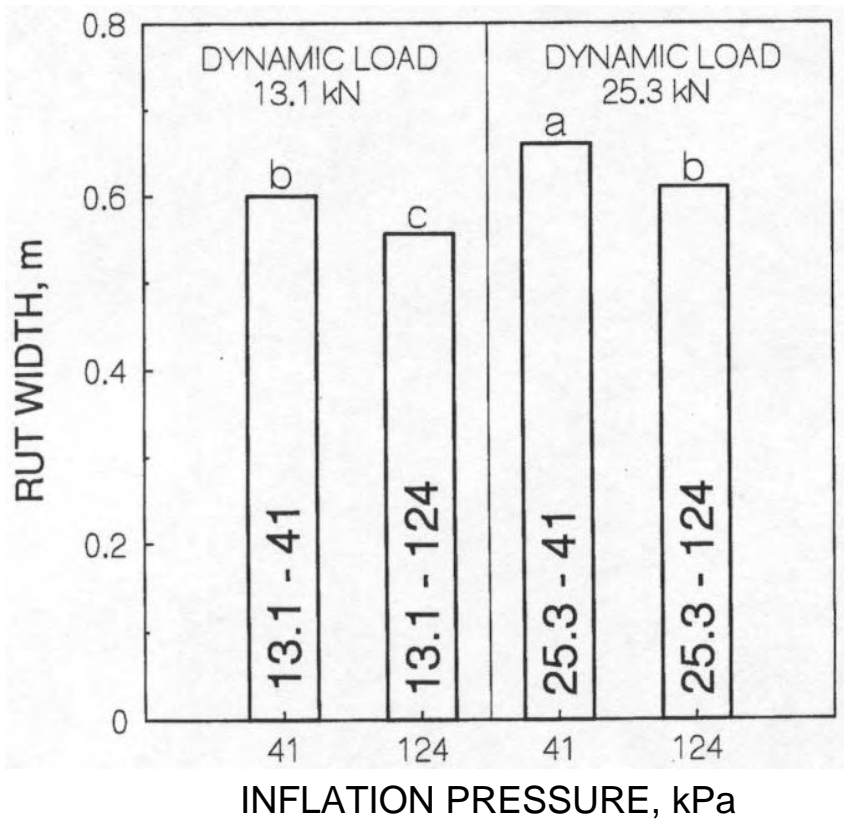

Figure 2-Average rut width across all soils and soil conditions as measured by a profile meter for the 18.4 R38 tire. LSD $(0.0 .5)=0.149$.

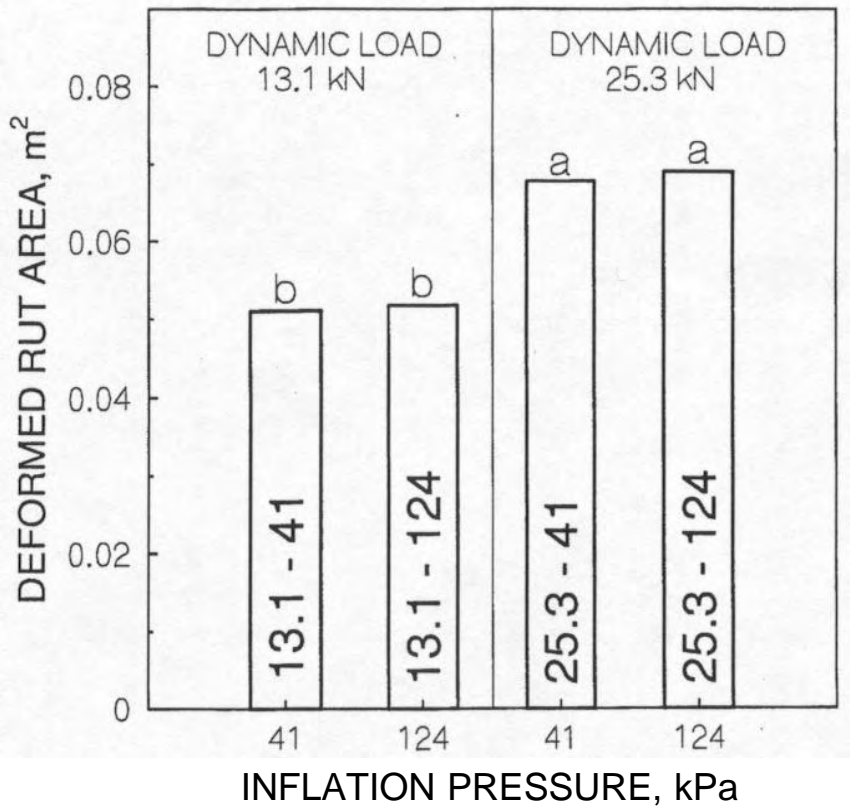

Figure 3-Average deformed area across soil types and soil conditions as measured by a profile meter for the $18.4 \mathrm{R38}$ tire. $\operatorname{LSD}(0.05)=0.004$.

correlating with increased deformed cross-sectional area $(p<0.0001)$.

A contact angle for each transducer is obtained by subtracting the angle that the transducer first comes in contact with the soil from the angle that it exits the soil. The following equation from the law of cosines was then used to determine a contact length for each transducer on the lug.

$$
\mathrm{L}=\mathrm{R} \sqrt{2(1-\cos \theta)}
$$

where

$$
\mathrm{L}=\text { contact length }(\mathrm{m})
$$

$\mathrm{R}=\operatorname{rolling}$ radius $(\mathrm{m})$

$\theta=$ contact angle

Inflation pressure and dynamic load statistically affect contact length of each of the transducers on the lug $(p<0.05)$ as shown in figure 4 . Increased inflation pressure decreased contact length, while increased dynamic load increased contact length.

Results from previous research has indicated that a reduction in soil compaction and improvements in tractive efficiency and net traction result when inflation pressure was reduced to that recommended by the tire industry (Bailey et al., 1993; Raper et al., 1993). In this article, we have shown that the correct matching of inflation pressure to dynamic load also increased the contact length, and contact area of a correctly inflated tire over an excessively inflated tire.

If each soil-tire interface stress transducer on the lug of the tire is assigned a width that extends halfway to adjacent transducers, a contact area can be calculated for each transducer on the lug by multiplying the assigned transducer width by each transducer's contact length. Summing each transducers contact area and assuming symmetry enables a total contact area to be obtained for each test. Statistical analyses showed that inflation pressure 


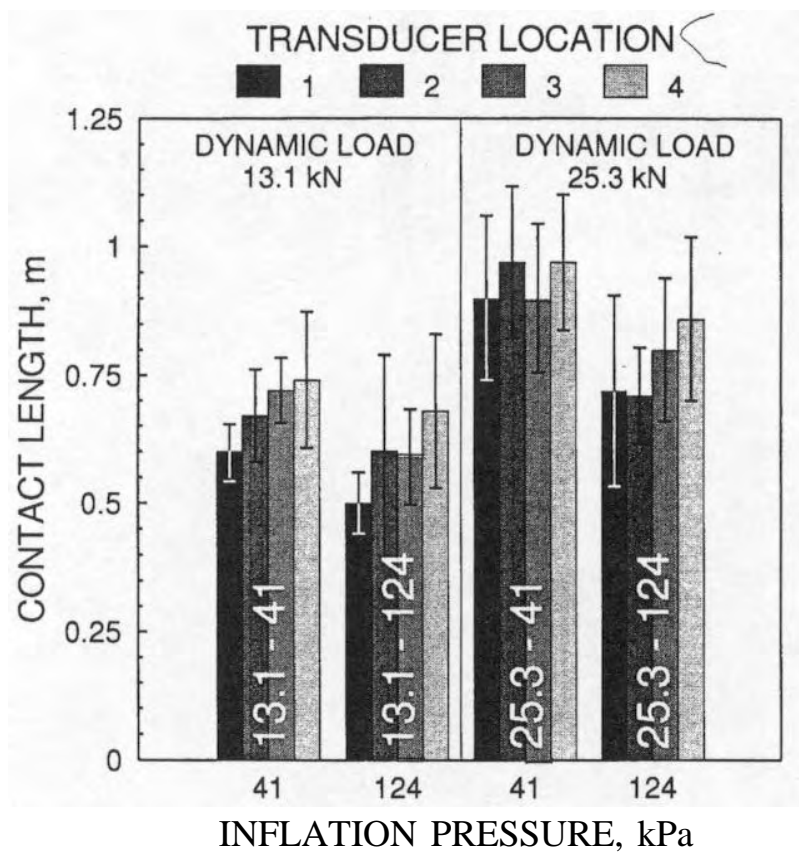

Figure 4-Average contact length across soil types and conditions as determined by the soil-tire interface transducers for the $18.4 \mathrm{R38}$ tire. The error bars indicate the standard deviations of the measurements

and dynamic load significantly affected contact area $(\mathrm{p}<0.001)$ (fig. 5). Figure 6 illustrates how the tire reacts when inflation pressure is increased above that recommended by the tire industry. As inflation pressure increases, not only does the entire footprint become shorter, the contact length near the outer edge of the tire decreases significantly.

The pressure data obtained from the soil-tire interface transducers can be used to analyze the stress distribution across the lug as it passes through the soil. Figures 7 and 8

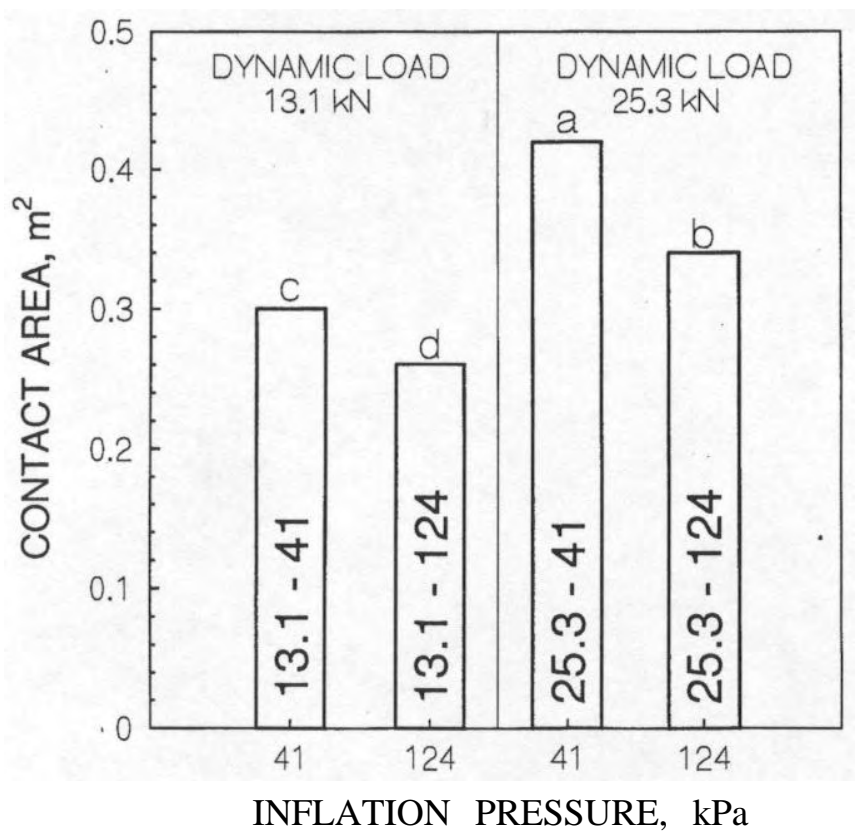

Figure 5-Average contact area across soil types and conditions as determined by the soil-tire interface transducers for the $18.4 \mathrm{R38}$ tire. $\operatorname{LSD}(0.05)=0.019$.

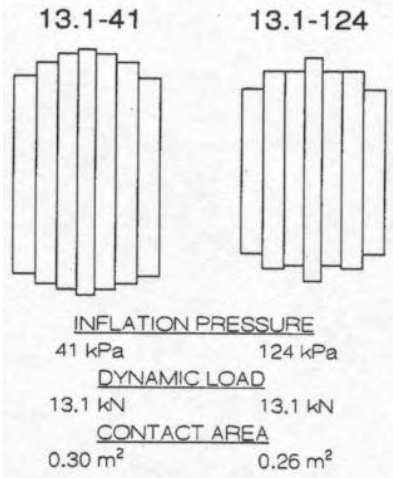

Figure 6-Contact area for the $18.4 \mathrm{R38}$ tire when subjected to the 13.1-41 and 13.1 - 124 load treatments

show the soil-tire interface stress distributions across the lug for each of the inflation pressure-dynamic load combinations. These data, collected for one lug, were assumed to occur symmetrically on the other side of the tire at the same position and were averaged across all replications, both soils, and both soil conditions. The resulting figures are not average stress distributions under the tire because of the undertread areas and other size lugs that have been neglected. These figures only show the soiltire interface stresses measured on the surface of the tire lug as it is passed through the soil.

The lower inflation pressures tended to concentrate more of the load near the edge of the tire (left half of figs. 7 and 8). while higher inflation pressures concentrated more of the load near the center of the tire (right half of figs. 7 and 8). Dynamic load effects arc illustrated by comparing figures 7 and 8 . On the right of figure 7 , soil-tire interface stress values near $120 \mathrm{kPa}$ (approximately the inflation pressure) were found near the center of the tire. When the load was increased and inflation pressure was maintained at $124 \mathrm{kPa}$ (as on the right of fig. 8). the load spreads across the width of the tire and the soil-tire interface stress exceeded $140 \mathrm{kPa}$ in the small circular areas near the rear center of the tire.

Contours of $25 \mathrm{kPa}$ were used to determine the area of the graphs that contained a certain interface stress range. The results (fig. 9) showed how increased inflation

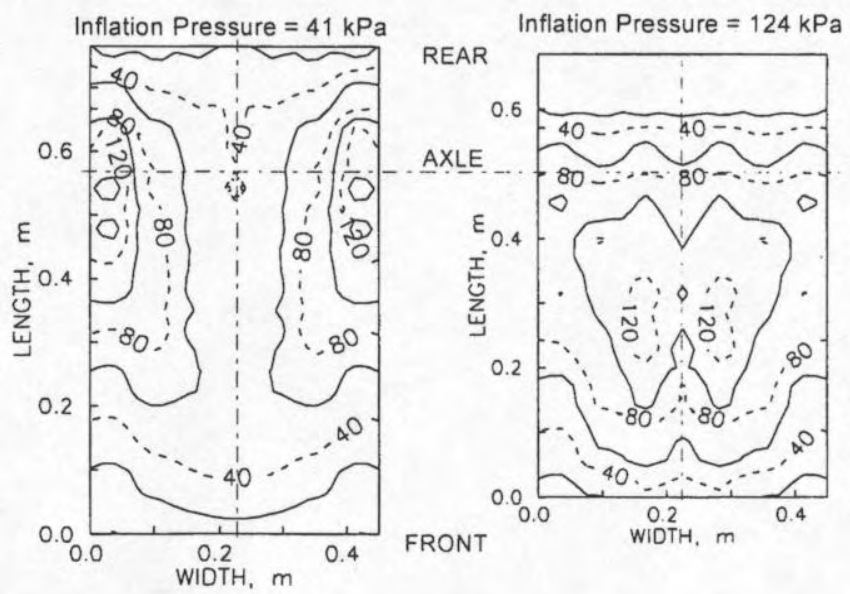

Figure 7-Soil-tire interface stress (kPa) distribution across the lug and assumed symmetric for an $18.4 \mathrm{R38}$ tire with dynamic loads of $13.1 \mathrm{kN}$ and inflation pressures of $41 \mathrm{kPa}$ at the left and $124 \mathrm{kPa}$ at the right. 


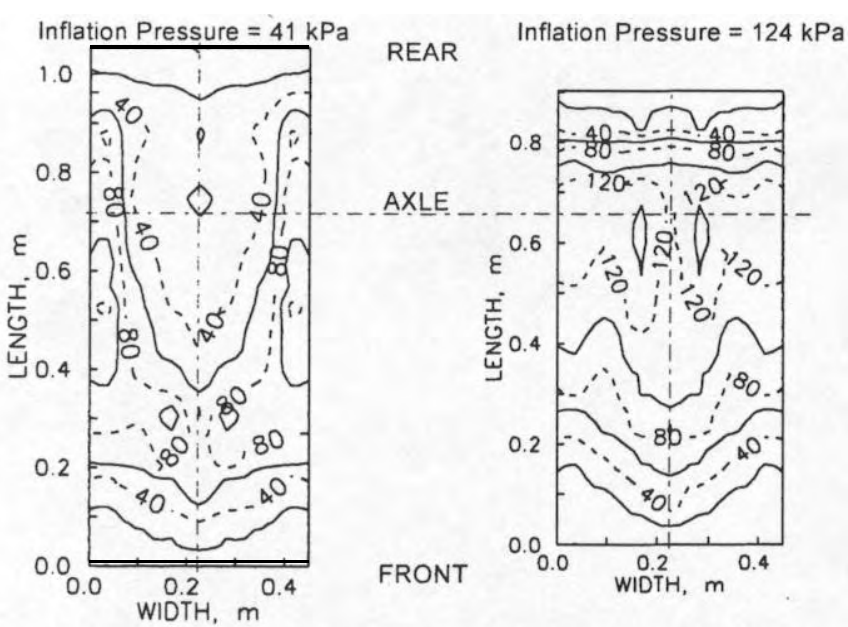

Figure 8-Soil-tire interface stress $(\mathrm{kPa})$ distribution across the lug and assumed symmetric for an $18.4 \mathrm{R38}$ tire with with dynamic loads of $25.3 \mathrm{kN}$ and with inflation pressures of $41 \mathrm{kPa}$ at the left and $124 \mathrm{kPa}$ at the right.

pressure affected stress distribution. For the 13.1 - 41 load combination. more than $75 \%$ of the area was subjected to stresses less than $75 \mathrm{kPa}$, while for the 13.1 - 124 load combination, less than $40 \%$ of the area had stresses in this range. More than $60 \%$ of the area had stresses in excess of $75 \mathrm{kPa}$ for the 13.1- 124 load combination.

The soil-tire interface stress distribution graphs show the transition of load that occurs when inflation pressure or dynamic load was increased. When inflation pressure was increased, the footprint of the tire decreased in size and the load was consolidated more near the center of the tire and away from the edges. Reducing the size of the area over which excessive values of soil-tire interface stress are present, or changing its location to near the tire edge may be as important as reducing the values themselves.

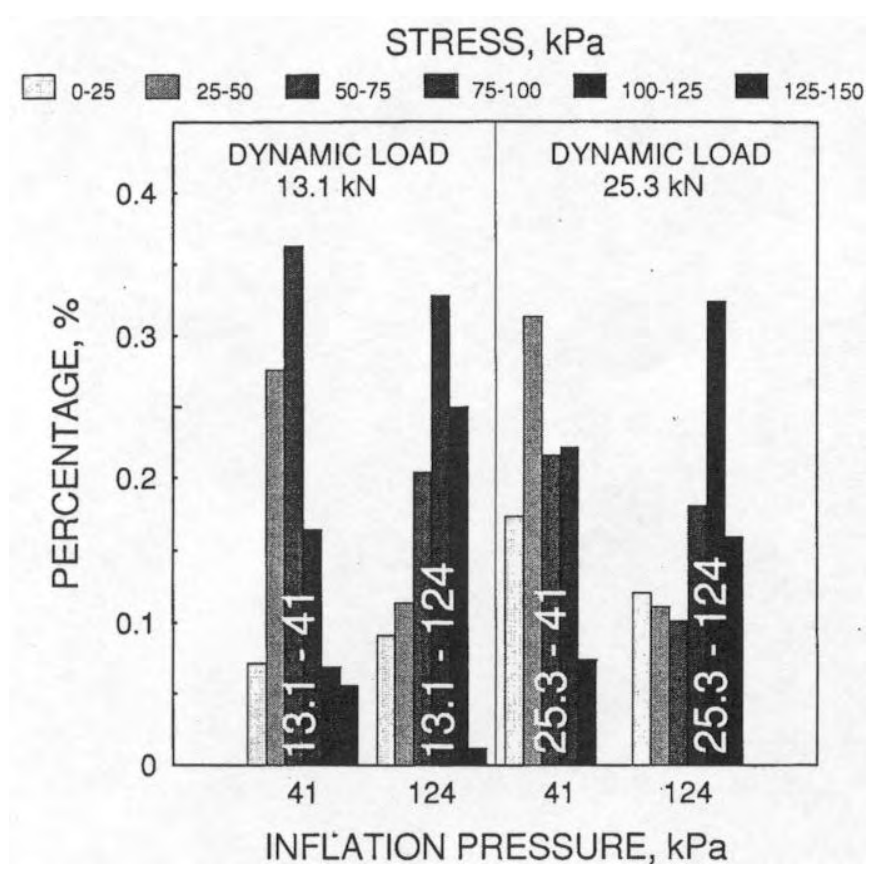

Figure 9-Percentage of stress found in the soil-tire distribution footprints for each of the load combinations for the $18.4 \mathrm{R38}$ tire.

\section{CONCLUSIONS}

- Increased inflation pressure decreased rut width, but had little effect on deformed soil cross-sectional area. Increased dynamic load increased both rut width and deformed soil cross-sectional area.

- Increased inflation pressure decreased bath the total contact length and the total contact area of the tire, while increased dynamic load increased both of these parameters.

- Increased inflation pressure caused the level of soiltire interface stresses to increase overall and to concentrate near the center of the tire. Increased dynamic load increased the levels of soil-tire interface stresses, particularly near the center of the tire.

ACKNOWLEDGMENT. The authors wish to acknowledge the contributions of Deere and Company and The Goodyear Tire and Rubber Company.

\section{REFERENCES}

Abeels, P. F. J. 1976. Tire deflection and contact studies. J. of Terramechanics 13(3):183-196.

Bailey, A. C.. R. L. Raper, T. R. Way, E. C. Bun and C. E. Johnson. 1993. Soil stresses under tractor tires at various inflation pressures. In Proc. of the 11th Annual Conf. of ISTVS, 276-285. Lake Tahoe, Nev., 27-30 Sept. 1993.

Burt, E. C. and A. C. Bailey. 1982. Load and inflation pressure effects on tires. Transactions of the ASAE 25(4):881-884.

Burt E. C., C. A. Reaves, A. C. Bailey and W. D. Pickering. 1980. A machine for testing tractor tires in soil bins. Transactions of the ASAE 23(3):546-547,552.

Erbach. D. C. and K. K. Knoll. 1992. Inflation pressure effect on soil compaction. ASAE Paper 92-1582. St. Joseph, Mich.: ASAE

Firestone. 1992. Maximize tractive performance of radial rear tractor tires with proper inflation. (February). Bridgestone/Firestone Inc.

Forrest, P. J. 1954. Effects of improper inflation pressures on farm tractor tires. Agricultural Engineering 35( 12):853-854.

Forrest, P J., I. F. Reed and G. V. Constantakis. 1962. Tractive characteristics of radial-ply tires. Transactions of the ASAE 5(2): 108,115 .

Goodyear. 1992. Optimum tractor tire performance handbook. (January). The Goodyear Tire \& Rubber Company.

John Deere. 1992. "New" radial tire inflation pressure recommendations. Tractor Talk (February).

Komandi, G. 1976. The determination of the deflection. contact area, dimensions, and load carrying capacity for driven pneumatic tires operating on concrete pavement $J$. of Terramechanics 13(1):15-20.

Lyne, P. W. L., B. C. Burt and J. D. Jarrell. 1983. Computer control for the National Tillage Machinery Laboratory single-wheel tester. ASAE Paper No. 83-1555. St. Joseph, Mich.: ASAE.

Raper, R. L., A. C. Bailey, E. C. Burt, T. R. Way and P. Liberati. 1993. Inflation pressure effects on soil-tire interface stresses. In Proc. of the 11th Annual Conf. of ISTVS, 781-790. Lake Tahoe, Nev., 27-30 Sept. 1993.

Reichcenberger, L 1992. Radial tires need "checks". Farm J. (reprint). (February).

Upadhyaya. S. K. and D. Wulfsohn. 1990. Relationship between tire deflection characteristics and 2-D tire contact area Transactions of the ASAE 33(1):25-30.

Wiley, J. C., B. E. Romig, L. V. Anderson and F. M. Zoz. 1992. Optimizing dynamic stability and perfomance of tractors with radial tires. ASAE Paper 92-1586. St Joseph. Mich.: ASAE.

Wood, R. K. and D. A. Mangione. 1992. Tractive benefits of properly adjusted inflation pressures: Farmer experiences. ASAE Paper No. 92-1583. St. Joseph, Mich.: ASAE. 